\title{
The Antiproliferative and Apoptotic Effects of Sirtinol, a Sirtuin Inhibitor on Human Lung Cancer Cells by Modulating Akt/ $\beta$-Catenin-Foxo3A Axis
}

\author{
Yao Fong, ${ }^{1}$ Yin-Chieh Lin, ${ }^{2}$ Chang-Yi Wu, ${ }^{3}$ Hui-Min David Wang, ${ }^{4}$ Li-Li Lin, ${ }^{5}$ \\ Han Lin Chou, ${ }^{2}$ Yen-Ni Teng, ${ }^{6}$ Shyng-Shiou Yuan, ${ }^{7}$ and Chien-Chih Chiu ${ }^{2,3,7}$ \\ ${ }^{1}$ Department of Thoracic Surgery, Chi-Mei Medical Center, Tainan 710, Taiwan \\ ${ }^{2}$ Department of Biotechnology, Kaohsiung Medical University, Kaohsiung 807, Taiwan \\ ${ }^{3}$ Department of Biological Sciences, National Sun Yat-sen University, 70 Lien Hai Road, Kaohsiung 804, Taiwan \\ ${ }^{4}$ Department of Fragrance and Cosmetics Science, Kaohsiung Medical University, Kaohsiung 807, Taiwan \\ ${ }^{5}$ Department of Medical Research, Kaohsiung Medical University Hospital, Kaohsiung Medical University, Kaohsiung 807, Taiwan \\ ${ }^{6}$ Department of Biological Sciences and Technology, National University of Tainan, Tainan 700, Taiwan \\ ${ }^{7}$ Translational Research Center, Cancer Center, Department of Medical Research, and Department of Obstetrics and Gynecology, \\ Kaohsiung Medical University Hospital, Kaohsiung Medical University, Kaohsiung 807, Taiwan
}

Correspondence should be addressed to Chien-Chih Chiu; cchiu@kmu.edu.tw

Received 18 June 2014; Revised 29 June 2014; Accepted 30 June 2014; Published 12 August 2014

Academic Editor: Li-Yeh Chuang

Copyright (C) 2014 Yao Fong et al. This is an open access article distributed under the Creative Commons Attribution License, which permits unrestricted use, distribution, and reproduction in any medium, provided the original work is properly cited.

\begin{abstract}
Sirtuins, $\mathrm{NAD}^{+}$-dependent deacetylases, could target both histones and nonhistone proteins in mammalian cells. Sirtl is the major sirtuin and has been shown to involve various cellular processes, including antiapoptosis, cellular senescence. Sirtl was reported to be overexpressed in many cancers, including lung cancer. Sirtinol, a specific inhibitor of Sirtl, has been shown to induce apoptosis of cancer cells by elevating endogenous level of reactive oxygen species. In the study, we investigated the effect of sirtinol on the proliferation and apoptosis of nonsmall cell lung cancer (NSCLC) H1299 cells. The results of proliferation assay and colony formation assay showed the antigrowth effect of sirtinol. The annexin-V staining further confirmed the apoptosis induction by sirtinol treatment. Interestingly, the levels of phosphorylated Akt and $\beta$-catenin were significantly downregulated with treating the apoptotic inducing doses. On the contrary, sirtinol treatment causes the significantly increased level of FoxO3a, a proapoptotic transcription factor targeted by Sirtl. These above results suggested that sirtinol may inhibit cell proliferation of H1299 cells by regulating the axis of Akt- $\beta$-catenin-FoxO3a. Overall, this study demonstrates that sirtinol attenuates the proliferation and induces apoptosis of NSCLC cells, indicating the potential treatment against NSCLC cells by inhibiting Sirtl in future applications.
\end{abstract}

\section{Introduction}

Cancer is one of the leading causes of death worldwide. Lung cancer has higher mortality than other cancers in both men and women [1]. More than $80 \%$ of lung cancer patients are nonsmall cell lung cancer (NSCLC). NSCLC can be classified by the location, including adenocarcinoma, squamous cell carcinoma, and large cell lung carcinoma $[2,3]$. The treatment options for patients with NSCLC include surgery, radiation therapy, chemotherapy, and targeted therapy. Chemotherapy is given as main treatment for more advanced cancers or for patients who are not healthy enough for surgery [4]. The chemotherapy for NSCLC treatment is developed and improved recently. However, the poor prognosis and drug resistance contribute to the low survival rate of NSCLC patients $[5,6]$.

Sirtuin (Sirt) family is a class III HDAC. In yeast, sirtuin protein plays an important role for lifespan extension in response to metabolic and other environmental stresses [710]. SIRT family proteins also target various nonhistone proteins including structural protein, signal intermediates, and transcription factors [11]. At least seven homologues (Sirt1-7) 
have been identified in mammalian cells [12-14]. Among Sirt proteins, the physiological role of Sirtl in mammalian cells has been reported to prevent tumorigenesis and ensure cellular longevity, and the continuous prevention of apoptosis may induce the tumorigenesis [15]. Previous studies showed that Sirtl overexpression in cancer correlates with silencing of tumor suppressor genes [16].

Akt is a serine/threonine kinase which has been shown to be associated with proliferation and survival [17]. The overexpression and constitutively activation of Akt was observed in many cancers, including lung cancer [6] and breast cancer [5] cells, which are highly correlated with the chemoresistance of cancer cells. On the contrary, Forkhead box O3a (FoxO3a), a transcription factor, is the downstream target of Akt [17]. FoxO3a can promote anticell growth or apoptosis signaling through either inducing expression of the proapoptotic Bcl-2 such as Bim [18], stimulating the expression of death receptor ligands, including Fas ligand and tumor necrosis factorrelated apoptosis-inducing ligand (TRAIL), or increasing the protein levels of cyclin-dependent kinase inhibitors [19]. Aberrant Akt-mediated phosphorylation of FoxO3a causes the survival and proliferation of cancer cells. Therefore, the signaling axis of Akt and FoxO3a regulates cell growth and survival may shed the light on developing a promising strategy for lung cancer treatment [17, 18, 20, 21].

The tumor suppressor forkhead family of transcription factors (FOXO) is one of SIRT1 substrate. The acetylation of FOXO3 increases in response to oxidative stress [22]. Therefore, FOXO3 could control the balance between stress resistance and apoptosis through its downstream targets such as GADD45 and Bim [23]. For example, Frazzi's work reported that resveratrol-induced apoptosis of Hodgkin lymphoma cells is involved in the inhibition of SIRT1 and the hyperacetylation of FoxO3 [24].

In this study, we demonstrated antigrowth and apoptosisinducing effect of sirtinol on lung cancer cells. The sirtinolinduced antiproliferation and apoptosis of lung cancer via FoxO3a-Akt were investigated and discussed.

\section{Methods}

2.1. Reagents. Sirtinol was purchased from Calbiochem (Darmstadt, Germany). Sirtinol was dissolved in 100\% DMSO at concentration of $10 \mathrm{mM}$ and stored at $-20^{\circ} \mathrm{C}$ until use. The following compounds were obtained from Gibco BRL (Maryland, USA): Dulbecco's modified eagle medium (DMEM), Ham's F-12 Nutrient Mixture (F-12) fetal bovine serum (FBS), trypan blue, penicillin $\mathrm{G}$, and streptomycin. Dimethyl sulfoxide (DMSO), ribonuclease A (RNase A), and propidium iodide (PI) were purchased from Sigma-Aldrich (Missouri, USA). Antibodies against FoxO3a were obtained from Epitomics (California, USA). Annexin V-FITC staining kit was purchased from Strong Biotech (Taipei, Taiwan). Antibodies against phospho-Akt, $\beta$-catenin, Sirtl, and $\beta$ actin were purchased from Santa Cruz Biotechnology (California, USA). Anti-mouse and anti-rabbit IgG peroxidaseconjugated secondary antibodies were purchased from Pierce
(Illinois, USA). The anti-rabbit Rhodamine-conjugated antibody was purchased from Abcam (Cambridge, UK).

2.2. Cell Culture. Human nonsmall cell lung cancer (NSCLC) cell lines H1299 were obtained from American Type Culture Collection (ATCC; Virginia, USA). All tested cells were maintained in DMEM/F-12 in 1:1 ratios ( $\mathrm{pH}$ 7.4) supplemented with $10 \%$ FBS and $1 \%$ penicillin-streptomycin $(100$ units $/ \mathrm{mL}$ penicillin and $100 \mu \mathrm{g} / \mathrm{mL}$ streptomycin). All cells were incubated in a humidified atmosphere incubator containing 5\% $\mathrm{CO}_{2}$ at $37^{\circ} \mathrm{C}$.

2.3. Proliferation Assay. The cell proliferation of H1299 cells was determined by trypan blue dye exclusion assay [25] combined with Countess Automated Cell Counter performed according to the manufacturer's instruction (Invitrogen; California, USA). $1 \times 10^{5}$ cells were seeded in 12-well plates and treated with indicated concentrations of sirtinol $(0,10,20$, and $50 \mu \mathrm{M}$ ) for $24 \mathrm{~h}$ and $48 \mathrm{~h}$, respectively. After incubation, the cells were stained by $0.2 \%$ trypan blue and counted by Countess.

2.4. Apoptosis Assessment. To examine the apoptosis assessment of H1299 cells after being sirtinol treated, AnnexinV/PI double staining [26] was performed to detect the externalization of phosphatidylserine (PS). $3 \times 10^{5}$ cells were seeded onto a 6 -well plate and incubated for $24 \mathrm{~h}$ and treated with different concentrations of sirtinol $(0,5,10,20$, and $50 \mu \mathrm{M})$ for $24 \mathrm{~h}$, respectively. Afterwards, cells were harvested and stained by Annexin-V staining kit (Strong Biotech, Taipei, Taiwan) according to the manufacturer's manual. The cells were washed in $1 \times$ Annexin-V buffer (HEPES, $\mathrm{NaCl}$, $\mathrm{CaCl}_{2} \cdot 2 \mathrm{H}_{2} \mathrm{O}$ ) and stained by Annexin-V for $30 \mathrm{~min}$ in $37^{\circ} \mathrm{C}$ water bath. The cells were analyzed by flow cytometry (FACS Calibur; Becton Dickinson; California, USA). The results of apoptosis assessment were analyzed by using the FlowJo software (Treestar, Inc.; California, USA).

2.5. Colony Formation Assay. 100 cells were planted onto a 6-well plate, and, after $24 \mathrm{~h}$ incubation, the cells were treated with different concentrations of sirtinol $(0,10,20$, and $50 \mu \mathrm{M})$. After 15 days incubation, the colonies of cells were glutaraldehyde-fixed and stained with crystal violet $(0.01 \% \mathrm{w} / \mathrm{v})$ for $1 \mathrm{~h}$. The diameter of colonies was determined by Image-Pro Plus software (Media Cybernetics; Maryland, USA).

2.6. Cell Cycle Analysis. $3 \times 10^{5}$ cells were seeded in 6-well plates and incubated for $24 \mathrm{~h}$. The cells were treated with different concentrations of sirtinol $(0,10,20$, and $50 \mu \mathrm{M})$ for $24 \mathrm{~h}$. Then, the cells were harvested and fixed with ice-cold $75 \%$ ethanol for at least $24 \mathrm{~h}$ at $-20^{\circ} \mathrm{C}$. Ethanol-fixed cells were collected by centrifugation and washed with PBS. After centrifugation, the cells were resuspended in $500 \mu \mathrm{L}$ PBS containing $2.5 \mu \mathrm{g} / \mathrm{mL}$ RNase A and incubated for $30 \mathrm{~min}$ in $37^{\circ} \mathrm{C}$ water bath. Then, the cells were centrifuged and stained by propidium iodide (PI) [27]. The cells were analyzed by flow 
cytometry. The cell cycle distribution results were analyzed by using the FlowJo software [28].

2.7. Western Blot Analysis. $6 \times 10^{5}$ cells were harvested and lysed with $1 \times$ RIPA lysis buffer. Lysates were centrifuged at $13000 \mathrm{rpm}$ for $30 \mathrm{~min}$ and the protein concentration in the supernatant was determined. $40 \mu \mathrm{g}$ of protein was resolved by $10 \%$ SDS-polyacrylamide gel electrophoresis (SDS-PAGE). Afterwards, the proteins were electrotransferred to the nitrocellulose membrane (PALL; Michigan, USA) and blocked with $5 \%$ fat-free milk in PBS-T buffer $(1 \times$ PBS containing $0.1 \%$ Tween 20 ) for $1 \mathrm{~h}$. Then the membranes were incubated with primary antibodies against specific proteins overnight at $4^{\circ} \mathrm{C}$. The blot was washed by PBS-T buffer and incubated with corresponding secondary antibodies for $90 \mathrm{~min}$. The signals were detected by an enhanced chemiluminescence (ECL) detection kit (Amersham Piscataway; New Jersey, USA) [29].

2.8. Statistical Analysis. Differences between DMSO- and sirtinol-treated cells were analyzed in at least triplicate experiments. The significance of the differences was analyzed by Student's $t$-test, with $P<0.05$ considered significantly.

\section{Results}

3.1. Sirtinol Exerts Antiproliferative Effect towards NSCLC Cells. We used sirtinol, a specific and direct inhibitor of the sirtuin class of deacetylase activity, to inhibit Sirtl in H1299 cells [30]. To investigate the effect of sirtinol on cell proliferation, the NSCLC cell line H1299 was treated with different concentrations of sirtinol for 24 and $48 \mathrm{~h}$, respectively. The cell viable cells were measured by trypan blue staining assay combined with automatic cell counter. The results of both cell proliferation assay and colony formation assay showed the antigrowth effect of sirtinol on NSCLC H1299 cells, especially at the dose of 20 and $50 \mu \mathrm{M}$ sirtinol treatment (Figures 1 and 2). We also examined whether sirtinol induced NSCLC H1299 cells apoptosis. We treated the cells with different concentrations of sirtinol $(0,10,20$, and $50 \mu \mathrm{M})$ and then conducted the flow cytometry-based Annexin V and PI double staining assay. The cellular apoptosis was detected at high concentration of sirtinol treatment (Figure 4).

3.2. The Effect of Sirtinol on Regulating Cell Cycle Distribution of H1299 Cells. In previous study, Sirtl has shown to exert the ability to induce cell cycle arrest and resistance to oxidative stress [31]. Therefore, we examined whether sirtinol induced NSCLC H1299 cell cycle disturbance. After sirtinol treatment, the cells were stained by PI, and detected the cell cycle distribution by flow cytometry (Figure 3 ). The result showed that the highest dose $(50 \mu \mathrm{M})$ of sirtinol treatment induces G1-phase accumulation.

3.3. The Effect of Sirtinol on Modulating the Expression of Prosurvival Proteins. Sirtl was reported to deacetylate various nonhistone protein targets, including $\mathrm{p} 53, \mathrm{NF}-\kappa \mathrm{B}, \beta$-catenin, and FoxO3a [32-34]. Because H1299 cells do not express the tumor suppressor p53 protein, we used Western blot

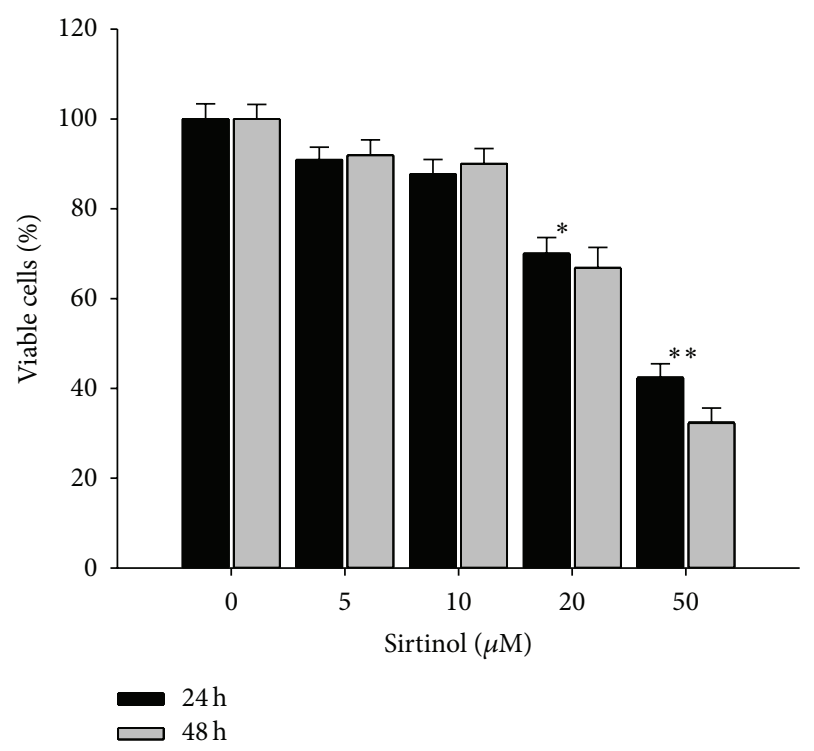

FIGURE 1: Effect of sirtinol on cellular proliferation of H1299 cells. H1299 cells treated with different concentrations (5, 10, 20 and $50 \mu \mathrm{M}$ ) of sirtinol for $24 \mathrm{~h}$ and $48 \mathrm{~h}$, respectively. The cell survival was determined by the trypan blue staining assay combined with the Countess Automated Cell Counter. ${ }^{* *} P<0.001$ against vehicle control.

to analyze the protein level of $\beta$-catenin, NF- $\kappa \mathrm{B}$ p 65 , and FoxO3a after sirtinol treatment (Figure 5 ). NF- $\kappa \mathrm{B}$ p65 is a critical transcription factor that regulates inflammation and cell proliferation and differentiation. NF- $\kappa \mathrm{B}$ was reported to be aberrantly expressed and constitutively activated in lung cancer $[35,36]$. However, the results of Western blot showed that no significant changes of $\mathrm{NF}-\kappa \mathrm{B}$ p 65 protein levels were observed (data not shown), suggesting that the antiproliferative effect of sirtinol on lung cancer H1299 cells is NF- $\kappa$ B p 65 -independent. On the contrary, the previous study showed that sirtl plays a tumor suppressive role mediated through inhibition of $\beta$-catenin [37]. The protein level of $\beta$ catenin was decreased only in cytotoxic concentrations 20 and $50 \mu \mathrm{M}$, suggesting that $\beta$-catenin did not involve in Sirtlinduced cells invasiveness, and Sirtl may play a role as a tumor promoter in H1299 cells.

The transcription factor FoxO3a has a crucial role in mediating the cytostatic and cytotoxic effects of anticancer drug [38, 39]. Recent study suggested that FoxO3a may be a major mediator for the cytotoxic effect of cisplatin in lung cancer cells [40]. More recently, Zheng's work demonstrated that ectopic expression of FoxO3a enhanced p2 $1^{\mathrm{CIP} 1 / \mathrm{WAF} 1}$ expression and berberine, a compound derived from traditional Chinese medicine-induced apoptosis in human lung adenocarcinoma cells [41], indicating the important role of FoxO3a in the initiation of apoptosis in cancer cells.

Furthermore, FoxO3a is a well-known nonhistone target of Sirtl. It has been reported that Sirtl would deacetylate and repress FoxO3a activity and reduce forkhead-dependent 


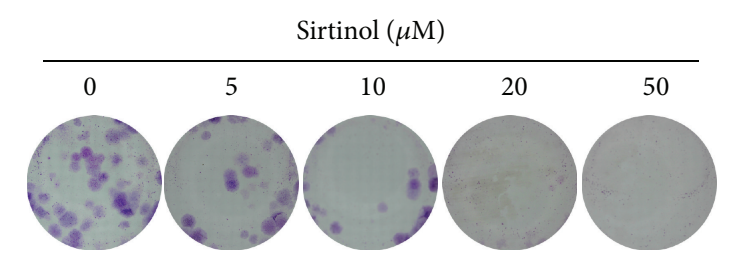

(a)

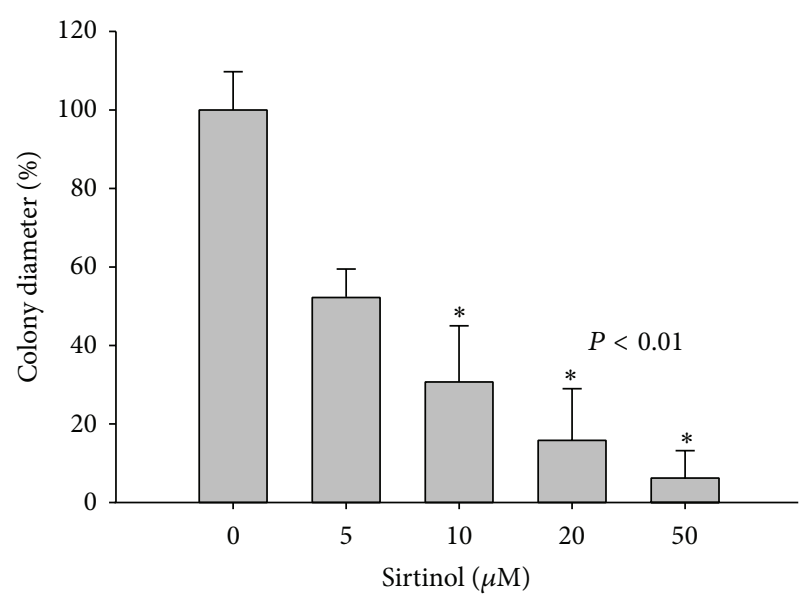

(b)

FIGURE 2: Sirtinol inhibits the colony formation of lung cancer cells. H1299 cells were treated with different concentrations (5, 10, 20 and $50 \mu \mathrm{M}$ ) of sirtinol for 15 days, respectively. Afterwards, the cells were glutaraldehyde-fixed and stained with Giemsa stain for $1 \mathrm{~h}$. (a) The colony formation analysis of H1299 cells. (b) The quantification analysis of the colony diameter. Data are represented as mean \pm SD $(n=3)$. ${ }^{*} P<0.01$ compared with the vehicle control.
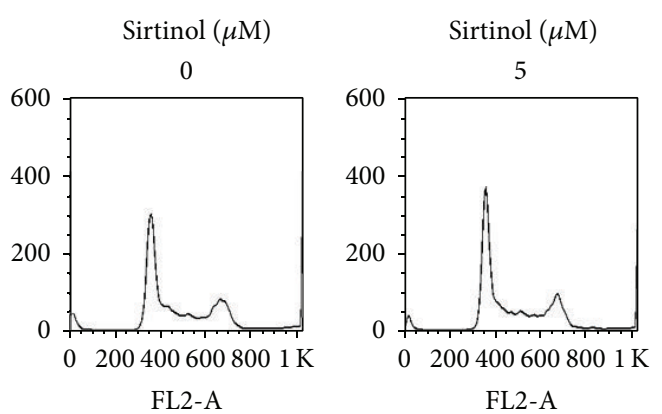

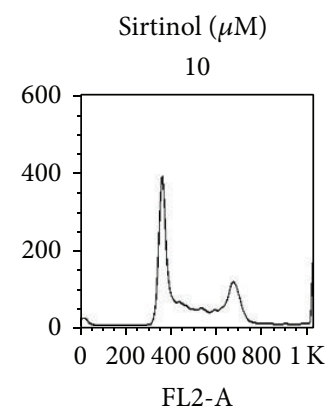

(a)
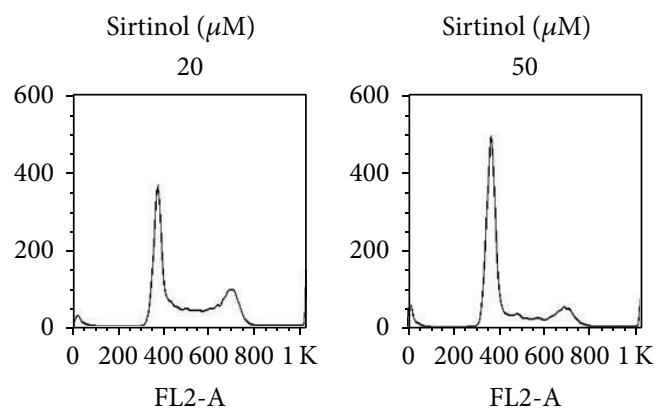

\begin{tabular}{lccccc}
\hline Phase $(\%) / \operatorname{dose}(\mu \mathrm{M})$ & 0 & 5 & 10 & 20 & 50 \\
\hline G0/G1 & $56.12 \pm 2.98^{a}$ & $55.32 \pm 2.89^{a}$ & $54.71 \pm 1.96^{a}$ & $54.14 \pm 2.37^{a}$ & $67.31 \pm 3.48^{c}$ \\
G2/M & $26.28 \pm 1.85^{a}$ & $28.38 \pm 4.19^{a}$ & $29.51 \pm 2.20^{b}$ & $29.39 \pm 2.76^{b}$ & $18.62 \pm 1.95^{c}$ \\
S & $14.49 \pm 1.79^{a}$ & $13.19 \pm 1.18^{a}$ & $12.76 \pm 0.91^{b}$ & $12.95 \pm 0.44^{b}$ & $8.85 \pm 1.40^{c}$ \\
Sub-G1 & $3.11 \pm 0.93^{a}$ & $3.11 \pm 0.68^{a}$ & $3.02 \pm 0.67^{a}$ & $3.52 \pm 0.09^{a}$ & $5.23 \pm 1.89^{b}$ \\
& & & & &
\end{tabular}

(b)

Figure 3: The effect of sirtinol on cell cycle distribution of lung cancer cells. H1299 cells treated with indicated concentrations (from 5 to $50 \mu \mathrm{M}$ ) of sirtinol for $24 \mathrm{~h}$, respectively. Cells were stained with PI and detected the cell cycle distribution by flow cytometry. (a) Flow cytometry profile represents PI staining in $x$-axis and cell number in $y$-axis. (b) The quantitative analysis of cell cycle distribution. Different letter notations indicate the statistical significance between drug treatment and vehicle ( $a$ versus $b$ and $a$ versus $c$ indicate the $P<0.05$ and 0.001 , resp.).

apoptosis [23]. In the result of Western blot, FoxO3a was increased after sirtinol treatment, suggesting that Sirtl represses the protein level of FoxO3a in NSCLC H1299 cells.

We next examined the proteins that involve in cellular proliferation and metastasis protein, including the phosphorylation of Akt [42-44] (Figure 5). The phosphorylation of levels of Akt was decreased only in cytotoxic concentrations 20 and $50 \mu \mathrm{M}$, suggesting that Akt did not involve in sirtinol-induced inhibition of cells' invasiveness but the apoptosis pathway. 


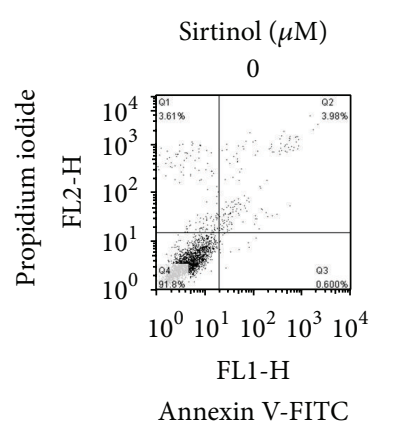

Annexin V-FITC

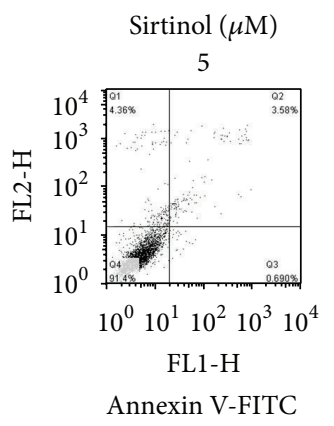

Annexin V-FITC
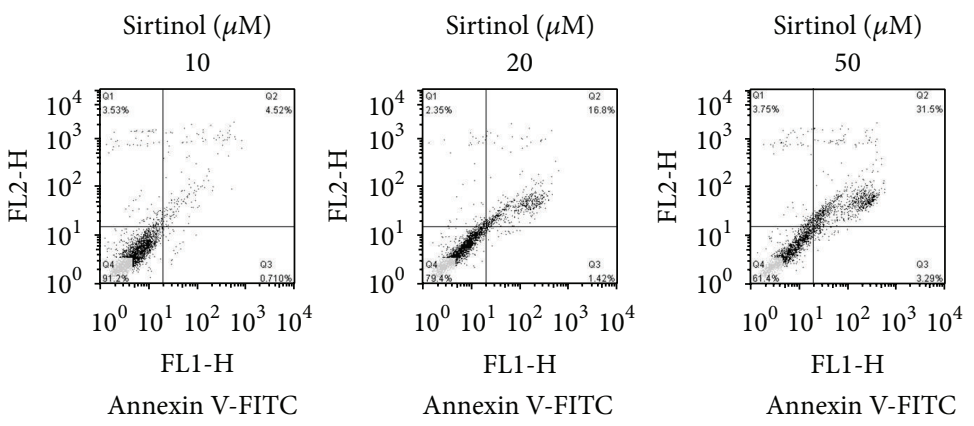

(a)

\begin{tabular}{lccccc}
\hline Phase $(\%) /$ dose $(\mu \mathrm{M})$ & 0 & 5 & 10 & 20 & 50 \\
\hline Necrosis $\left(\mathrm{A}^{-} \mathrm{P}^{+}\right)$ & $3.98 \pm 0.33^{a}$ & $4.21 \pm 0.36^{a}$ & $3.55 \pm 0.41^{a}$ & $2.47 \pm 0.11^{c}$ & $3.88 \pm 0.14^{a}$ \\
Late apoptosis $\left(\mathrm{A}^{+} \mathrm{P}^{+}\right)$ & $3.82 \pm 0.15^{a}$ & $3.47 \pm 0.27^{a}$ & $4.02 \pm 0.51^{a}$ & $16.3 \pm 1.04^{c}$ & $30.67 \pm 0.85^{c}$ \\
Early apoptosis $\left(\mathrm{A}^{+} \mathrm{P}^{-}\right)$ & $0.56 \pm 0.05^{a}$ & $0.71 \pm 0.08^{a}$ & $0.73 \pm 0.02^{a}$ & $1.53 \pm 0.12^{c}$ & $2.94 \pm 0.31^{c}$ \\
Healthy $\left(\mathrm{A}^{-} \mathrm{P}^{-}\right)$ & $91.63 \pm 0.21^{a}$ & $91.6 \pm 0.53^{a}$ & $91.7 \pm 0.78^{a}$ & $79.7 \pm 0.98^{c}$ & $62.47 \pm 1.05^{c}$ \\
\hline
\end{tabular}

(b)

Figure 4: Sirtinol induces apoptosis of H1299 cells. Cells were treated with indicated concentrations of sirtinol and stained with Annexin-V and PI at $24 \mathrm{~h}$, respectively. (a) Flow cytometry profiling represents the results of Annexin-V-FITC staining. (b) The quantificative analysis of cell apoptosis. Different letter notations indicate the statistical significance between sirtinol treatment and vehicle ( $a$ versus $b$ and $a$ versus $c$ indicate the $P<0.05$ and 0.001 , resp.).

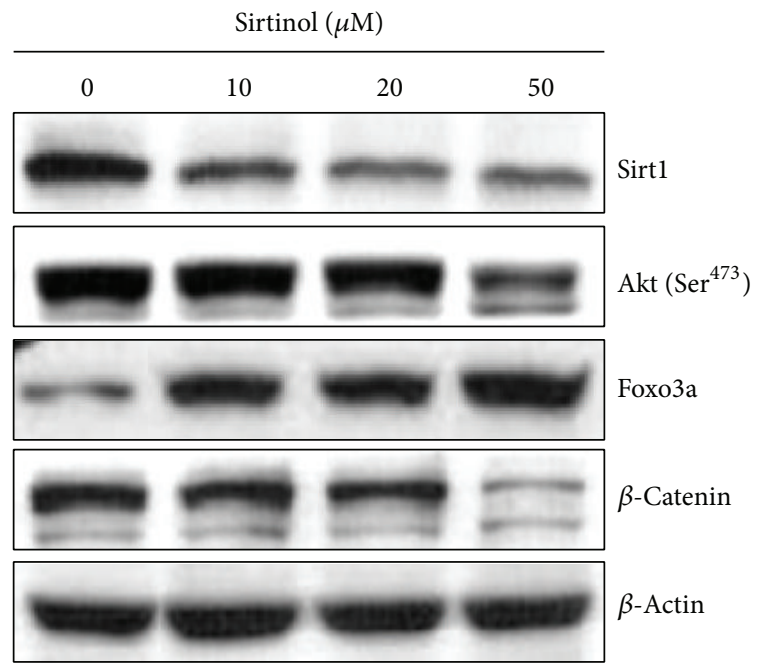

Figure 5: Modulation of protein levels in NSCLC H1299 cells after sirtinol treatment. H1299 cells treated with indicated concentrations $(10,20$, and $50 \mu \mathrm{M})$ of sirtinol for $24 \mathrm{~h}$, respectively. The results of Western blot of Sirtl nonhistone target protein, including FoxO3a, Akt phosphorylation, and $\beta$-catenin. $\beta$-Actin as an internal control.

\section{Discussion}

Sirtl has been shown to be involved in a variety of biological processes, including transcriptional silencing, stress responses, aging, apoptosis, tumorigenesis, and cellular metabolism
$[45,46]$. It targets diverse histone and various nonhistone proteins including structural protein, signal intermediates, and transcription factors, such as $\alpha$-tubulin, p53 [47-49], FoxO [20, 23, 31], E2F1 [50], NF- $\kappa \mathrm{B}[51,52]$, and Ku70 [53]. Additionally, Sirtl has been shown to overexpress in several cancer cells, including breast, prostate, ovarian, and colon cancer cell lines [46, 54-58]. Recent studies showed the tumorigenicity role of Sirt1. For example, Sirtl was reported to promote cell migration and invasion of prostate cancer $[59,60]$. Consistently, our preliminary result also showed that Sirtl would overexpress in NSCLC cell lines (data not shown).

The production of ROS has been resulted in cellular damage and genomic instability [61]. Furthermore, many anticancer drugs could induce apoptosis by increasing the level of endogenous ROS in the cancer cells $[62,63]$. Recent study showed that sirtinol treatment induces the apoptosis of lung carcinoma 549 cells by increasing the level of endogenous ROS [64].

Accordingly, we proposed the positive role of Sirtl in the progression of NSCLC cells. We used sirtinol, a specific inhibitor of sirtuin, to inhibit Sirtl. Our results showed that sirtinol exerts a significant cytotoxicity towards NSCLC H1299 cells with a dose-responsive manner (20 and $50 \mu \mathrm{M})$. The Western results showed that sirtinol-induced inhibition of Sirtl resulted in the increased transcription factor FoxO3a. These above results suggest a close correlation of sirtinolinduced antilung cancer and the regulation of Akt-FoxO3a signaling pathway (Figure 6). 


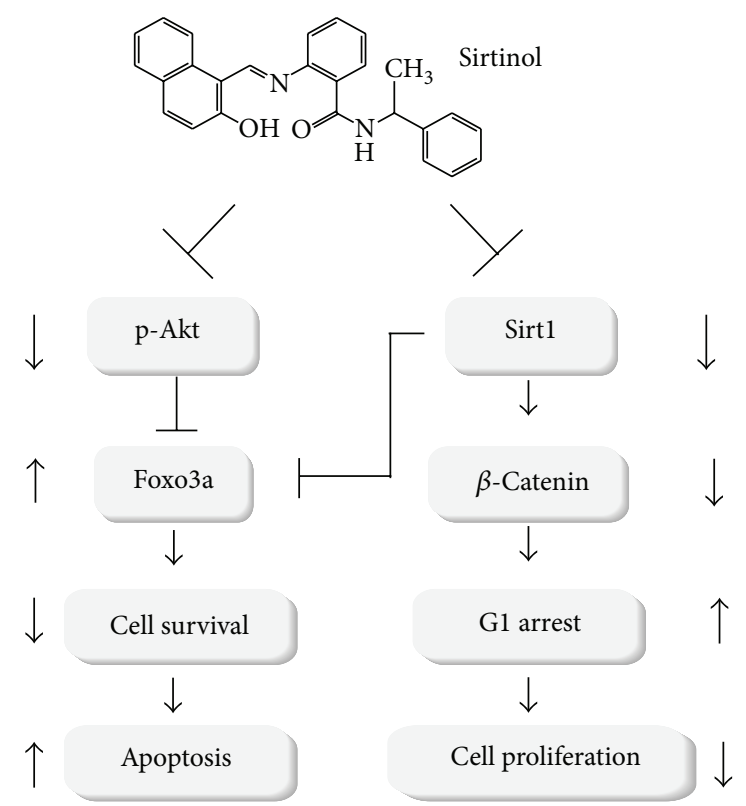

FIgUre 6: Possible model of sirtinol-induced antiproliferation and apoptosis in lung cancer cells. Sirtinol downregulates the activation of prosurvival Akt serine/threonine kinase and the protein level of $\beta$-catenin, a proliferation-associated transcription factor, insulting in the cell cycle $G_{1}$-phase accumulation and the growth arrest. On the contrary, sirtinol treatment causes the upregulation of the proapoptotic transcription factor FoxO3a, a target of both Akt signaling and Sirt1. This may render H1299 cells more sensitive to apoptosis. Finally, sirtinol induces the apoptosis of lung cancer cells.

\section{Conclusions}

In this study, we used sirtinol, a specific inhibitor of Sirtl, to investigate the role of Sirtl in the apoptosis and proliferation of H1299 cells. Sirtinol treatment causes the cell cycle arrest and apoptosis of lung cancer cells. Furthermore, sirtinolinduced inhibition of Sirtl activity may increase the protein levels of the transcription factor Foxoa3a whereas it downregulates the activation of Akt and the protein level of $\beta$ catenin after sirtinol treatment. Our recent work suggests that sirtinol-induced antiproliferation and apoptosis of lung cancer cells may be correlated with Akt-FoxO3a signaling pathway (Figure 6).

\section{Conflict of Interests}

The authors declare that they have no conflict of interests.

\section{Acknowledgments}

The study was financially supported by Grant no. NSC1012320-B-037-046-MY3 from the National Science Council, Taiwan, Grant nos. 101-CM-KMU-11 and 102-CM-KMU-09 from the ChiMei-KMU Joint Research Project, Grant no. NSYSUKMU102-P031 from the NSYSU-KMU Joint Research Project, and Grant no. MOHW103-TD-B-111-05 from the Ministry of Health and Welfare, Taiwan.

\section{References}

[1] M. Heron, "Deaths: leading causes for 2008," National Vital Statistics Reports: From the Centers for Disease Control and Prevention, National Center for Health Statistics, National Vital Statistics System, vol. 60, no. 6, pp. 1-94, 2012.

[2] D. L. Longo, Harrison's Principles of Internal Medicine, McGrawHill, New York, NY, USA, 2011.

[3] R. Siegel, D. Naishadham, and A. Jemal, "Cancer statistics, 2012," CA: A Cancer Journal for Clinicians, vol. 62, no. 1, pp. 10-29, 2012.

[4] S. Burdett, R. Stephens, L. Stewart et al., "Chemotherapy in addition to supportive care improves survival in advanced nonsmall-cell lung cancer: a systematic review and meta-analysis of individual patient data from 16 randomized controlled trialsNSCLC Meta-Analyses Collaborative Group," Journal of Clinical Oncology, vol. 26, no. 28, pp. 4617-4625, 2008.

[5] R. Pirker and W. Minar, "Chemotherapy of advanced non-small cell lung cancer," Frontiers of Radiation Therapy and Oncology, vol. 42, pp. 157-163, 2010.

[6] T. D. Wagner and G. Y. Yang, "The role of chemotherapy and radiation in the treatment of locally advanced non-small cell lung cancer (NSCLC)," Current Drug Targets, vol. 11, no. 1, pp. 67-73, 2010.

[7] K. T. Howitz, K. J. Bitterman, H. Y. Cohen et al., "Small molecule activators of sirtuins extend Saccharomyces cerevisiae lifespan," Nature, vol. 425, no. 6954, pp. 191-196, 2003.

[8] L. Guarente and F. Picard, "Calorie restriction-the SIR2 connection," Cell, vol. 120, no. 4, pp. 473-482, 2005.

[9] V. D. Longo and B. K. Kennedy, "Sirtuins in aging and agerelated disease," Cell, vol. 126, no. 2, pp. 257-268, 2006.

[10] L. Fontana, L. Partridge, and V. D. Longo, "Extending healthy life span-from yeast to humans," Science, vol. 328, no. 5976, pp. 321-326, 2010.

[11] Y. Olmos, J. J. Brosens, and E. W. F. Lam, "Interplay between SIRT proteins and tumour suppressor transcription factors in chemotherapeutic resistance of cancer," Drug Resistance Updates, vol. 14, no. 1, pp. 35-44, 2011.

[12] M. C. Haigis and D. A. Sinclair, "Mammalian sirtuins: biological insights and disease relevance," Annual Review of Pathology: Mechanisms of Disease, vol. 5, pp. 253-295, 2010.

[13] Y. Cen, D. Y. Youn, and A. A. Sauve, "Advances in characterization of human sirtuin isoforms: chemistries, targets and therapeutic applications," Current Medicinal Chemistry, vol. 18, no. 13, pp. 1919-1935, 2011.

[14] Y. Horio, T. Hayashi, A. Kuno, and R. Kunimoto, "Cellular and molecular effects of sirtuins in health and disease," Clinical Science, vol. 121, no. 5, pp. 191-203, 2011.

[15] C. L. Brooks and W. Gu, "How does SIRT1 affect metabolism, senescence and cancer?" Nature Reviews Cancer, vol. 9, no. 2, pp. 123-128, 2009.

[16] K. Pruitt, R. L. Zinn, J. E. Ohm et al., "Inhibition of SIRT1 reactivates silenced cancer genes without loss of promoter DNA hypermethylation," PLoS Genetics, vol. 2, no. 3, article e40, 2006.

[17] X. Zhang, N. Tang, T. J. Hadden, and A. K. Rishi, "Akt, FoxO and regulation of apoptosis," Biochimica et Biophysica Acta, vol. 1813, no. 11, pp. 1978-1986, 2011.

[18] Y. Lv, S. Song, K. Zhang, H. Gao, and R. Ma, "CHIP regulates AKT/FoxO/Bim signaling in MCF7 and MCF10A cells," PLoS ONE, vol. 8, no. 12, Article ID e83312, 2013. 
[19] J. Seoane, H. Le, L. Shen, S. A. Anderson, and J. Massagué, "Integration of smad and forkhead pathways in the control of neuroepithelial and glioblastoma cell proliferation," Cell, vol. 117, no. 2, pp. 211-223, 2004.

[20] N. Hariharan, Y. Maejima, J. Nakae, J. Paik, R. A. Depinho, and J. Sadoshima, "Deacetylation of FoxO by Sirtl plays an essential role in mediating starvation-induced autophagy in cardiac myocytes," Circulation Research, vol. 107, no. 12, pp. 1470-1482, 2010.

[21] C. Wu, B. Jin, L. Chen et al., "MiR-30d induces apoptosis and is regulated by the Akt/FOXO pathway in renal cell carcinoma," Cellular Signalling, vol. 25, no. 5, pp. 1212-1221, 2013.

[22] A. Brunet, L. B. Sweeney, J. F. Sturgill et al., "Stress-Dependent Regulation of FOXO Transcription Factors by the SIRT1 Deacetylase," Science, vol. 303, no. 5666, pp. 2011-2015, 2004.

[23] M. C. Motta, N. Divecha, M. Lemieux et al., "Mammalian SIRT1 represses forkhead transcription factors," Cell, vol. 116, no. 4, pp. 551-563, 2004.

[24] R. Frazzi, R. Valli, I. Tamagnini, B. Casali, N. Latruffe, and F. Merli, "Resveratrol-mediated apoptosis of hodgkin lymphoma cells involves SIRT1 inhibition and FOXO3a hyperacetylation," International Journal of Cancer, vol. 132, no. 5, pp. 1013-1021, 2013.

[25] C. Yen, C. Chiu, R. Haung et al., "Antiproliferative effects of goniothalamin on Ca9-22 oral cancer cells through apoptosis, DNA damage and ROS induction," Mutation Research-Genetic Toxicology and Environmental Mutagenesis, vol. 747, no. 2, pp. 253-258, 2012.

[26] C. Chiu, P. Liu, K. Huang et al., "Goniothalamin inhibits growth of human lung cancer cells through DNA damage, apoptosis, and reduced migration ability," Journal of Agricultural and Food Chemistry, vol. 59, no. 8, pp. 4288-4293, 2011.

[27] C. C. Chiu, H. W. Chang, D. W. Chuang et al., "Fern plantderived protoapigenone leads to DNA damage, apoptosis, and $\mathrm{g} 2 / \mathrm{m}$ arrest in lung cancer cell line H1299," DNA and Cell Biology, vol. 28, no. 10, pp. 501-506, 2009.

[28] L. Bonetta, "Flow cytometry smaller and better," Nature Methods, vol. 2, no. 10, pp. 785-794, 2005.

[29] C. Chiu, J. Haung, F. Chang et al., "Golden berry-derived $4 \beta$ hydroxywithanolide $\mathrm{E}$ for selectively killing oral cancer cells by generating ROS, DNA damage, and apoptotic pathways," PLoS ONE, vol. 8, no. 5, Article ID e64739, 2013.

[30] H. Ota, E. Tokunaga, K. Chang et al., "Sirt1 inhibitor, Sirtinol, induces senescence-like growth arrest with attenuated RasMAPK signaling in human cancer cells," Oncogene, vol. 25, no. 2, pp. 176-185, 2006.

[31] A. Brunet, L. B. Sweeney, J. F. Sturgill et al., "Stress-dependent regulation of FOXO transcription factors by the sirtl deacetylase," Science, vol. 303, no. 5666, pp. 2011-2015, 2004.

[32] H. Vaziri, S. K. Dessain, E. N. Eaton et al., "hSIR2SIRT1 functions as an NAD-dependent p53 deacetylase," Cell, vol. 107, no. 2, pp. 149-159, 2001.

[33] C. X. Deng, "SIRT1, is it a tumor promoter or tumor suppressor?" International Journal of Biological Sciences, vol. 5, no. 2, pp. 147-152, 2009.

[34] S. Nemoto, M. M. Fergusson, and T. Finkel, "Nutrient availability regulates SIRT1 through a forkhead-dependent pathway," Science, vol. 306, no. 5704, pp. 2105-2108, 2004.

[35] Y. Saitoh, V. J. Martínez Bruyn, S. Uota et al., "Overexpression of NF- $\kappa \mathrm{B}$ inducing kinase underlies constitutive NF- $\kappa \mathrm{B}$ activation in lung cancer cells," Lung Cancer, vol. 70, no. 3, pp. 263-270, 2010 .
[36] X. Tang, D. Liu, S. Shishodia et al., "Nuclear factor- $\kappa$ B (NF$\kappa \mathrm{B})$ is frequently expressed in lung cancer and preneoplastic lesions," Cancer, vol. 107, no. 11, pp. 2637-2646, 2006.

[37] R. Firestein, G. Blander, S. Michan et al., "The SIRT1 deacetylase suppresses intestinal tumorigenesis and colon cancer growth," PLoS ONE, vol. 3, no. 4, Article ID e2020, 2008.

[38] A. R. Gomes, J. J. Brosens, and E. W.-F. Lam, "Resist or die: FOXO transcription factors determine the cellular response to chemotherapy," Cell Cycle, vol. 7, no. 20, pp. 3133-3136, 2008.

[39] S. S. Myatt and E. W.-F. Lam, "The emerging roles of forkhead box (Fox) proteins in cancer," Nature Reviews Cancer, vol. 7, no. 11, pp. 847-859, 2007.

[40] H. Liu, J. Yin, C. Wang, Y. Gu, M. Deng, and Z. He, "FOXO3a mediates the cytotoxic effects of cisplatin in lung cancer cells," Anti-Cancer Drugs, vol. 25, no. 8, pp. 898-907, 2014.

[41] F. Zheng, Q. Tang, J. Wu et al., "p38alpha MAPK-mediated induction and interaction of FOXO3a and p53 contribute to the inhibited-growth and induced-apoptosis of human lung adenocarcinoma cells by berberine," Journal of Experimental \& Clinical Cancer Research, vol. 33, no. 1, p. 36, 2014.

[42] K. Kamitori, M. Tanaka, T. Okuno-Hirasawa, and S. Kohsaka, "Receptor related to tyrosine kinase RYK regulates cell migration during cortical development," Biochemical and Biophysical Research Communications, vol. 330, no. 2, pp. 446-453, 2005.

[43] M. Morales-Ruiz, D. Fulton, G. Sowa et al., "Vascular endothelial growth factor-stimulated actin reorganization and migration of endothelial cells is regulated via the serine/threonine kinase Akt," Circulation Research, vol. 86, no. 8, pp. 892-896, 2000.

[44] C. Huang, J. Liu, C. C. Haudenschild, and X. Zhan, "The role of tyrosine phosphorylation of cortactin in the locomotion of endothelial cells," Journal of Biological Chemistry, vol. 273, no. 40, pp. 25770-25776, 1998.

[45] T. Inoue, M. Hiratsuka, M. Osaki, and M. Oshimura, "The molecular biology of mammalian SIRT proteins: SIRT2 in cell cycle regulation," Cell Cycle, vol. 6, no. 9, pp. 1011-1018, 2007.

[46] W. Stünkel and R. M. Campbell, "Sirtuin 1 (SIRT1): the misunderstood HDAC," Journal of Biomolecular Screening, vol. 16, no. 10, pp. 1153-1169, 2011.

[47] J. Luo, A. Y. Nikolaev, S. Imai et al., "Negative control of p53 by Sir $2 \alpha$ promotes cell survival under stress," Cell, vol. 107, no. 2, pp. 137-148, 2001.

[48] E. Langley, M. Pearson, M. Faretta et al., "Human SIR2 deacetylates p53 and antagonizes PML/p53-induced cellular senescence," The EMBO Journal, vol. 21, no. 10, pp. 2383-2396, 2002.

[49] J. Yi and J. Luo, "SIRT1 and p53, effect on cancer, senescence and beyond," Biochimica et Biophysica Acta, vol. 1804, no. 8, pp. 1684-1689, 2010.

[50] C. Wang, L. Chen, X. Hou et al., "Interactions between E2F1 and SirT1 regulate apoptotic response to DNA damage," Nature Cell Biology, vol. 8, no. 9, pp. 1025-1031, 2006.

[51] L. Chen, W. Fischle, E. Verdin, and W. C. Greene, "Duration of nuclear NF- $\kappa \mathrm{B}$ action regulated by reversible acetylation," Science, vol. 293, no. 5535, pp. 1653-1657, 2001.

[52] A. Salminen, J. Ojala, J. Huuskonen, A. Kauppinen, T. Suuronen, and K. Kaarniranta, "Interaction of aging-associated signaling cascades: inhibition of NF- $\kappa \mathrm{B}$ signaling by longevity factors FoxOs and SIRT1," Cellular and Molecular Life Sciences, vol. 65, no. 7-8, pp. 1049-1058, 2008.

[53] J. Jeong, K. Juhn, H. Lee et al., "SIRT1 promotes DNA repair activity and deacetylation of Ku70," Experimental \& Molecular Medicine, vol. 39, no. 1, pp. 8-13, 2007. 
[54] W. Stünkel, B. K. Peh, Y. C. Tan et al., "Function of the SIRTI protein deacetylase in cancer," Biotechnology Journal, vol. 2, no. 11, pp. 1360-1368, 2007.

[55] K. Y. Jang, K. S. Kim, S. H. Hwang et al., "Expression and prognostic significance of SIRT1 in ovarian epithelial tumours," Pathology, vol. 41, no. 4, pp. 366-371, 2009.

[56] N. Kabra, Z. Li, L. Chen et al., "SirT1 is an inhibitor of proliferation and tumor formation in colon cancer," Journal of Biological Chemistry, vol. 284, no. 27, pp. 18210-18217, 2009.

[57] K. Nosho, K. Shima, N. Irahara et al., "SIRT1 histone deacetylase expression is associated with microsatellite instability and CpG island methylator phenotype in colorectal cancer," Modern Pathology, vol. 22, no. 7, pp. 922-932, 2009.

[58] B. Wang, M. K. Hasan, E. Alvarado, H. Yuan, H. Wu, and W. Y. Chen, "NAMPT overexpression in prostate cancer and its contribution to tumor cell survival and stress response," Oncogene, vol. 30, no. 8, pp. 907-921, 2011.

[59] Y. Zhang, M. Zhang, H. Dong et al., "Deacetylation of cortactin by SIRT1 promotes cell migration.," Oncogene, vol. 28, no. 3, pp. 445-460, 2009.

[60] K. Nakane, Y. Fujita, R. Terazawa et al., "Inhibition of cortactin and SIRT1 expression attenuates migration and invasion of prostate cancer DU145 cells," International Journal of Urology, vol. 19, no. 1, pp. 71-79, 2012.

[61] J. Lee, M. Hou, H. Huang et al., "Marine algal natural products with anti-oxidative, anti-inflammatory, and anti-cancer properties," Cancer Cell International, vol. 13, no. 1, article 55, 2013.

[62] H.-U. Simon, A. Haj-Yehia, and F. Levi-Schaffer, "Role of reactive oxygen species (ROS) in apoptosis induction," Apoptosis, vol. 5, no. 5, pp. 415-418, 2000.

[63] L. Khandrika, B. Kumar, S. Koul, P. Maroni, and H. K. Koul, "Oxidative stress in prostate cancer," Cancer Letters, vol. 282, no. 2, pp. 125-136, 2009.

[64] S. Pal, B. S. Shankar, and K. B. Sainis, "Cytokines from the tumor microenvironment modulate sirtinol cytotoxicity in A549 lung carcinoma cells," Cytokine, vol. 64, no. 1, pp. 196-207, 2013. 

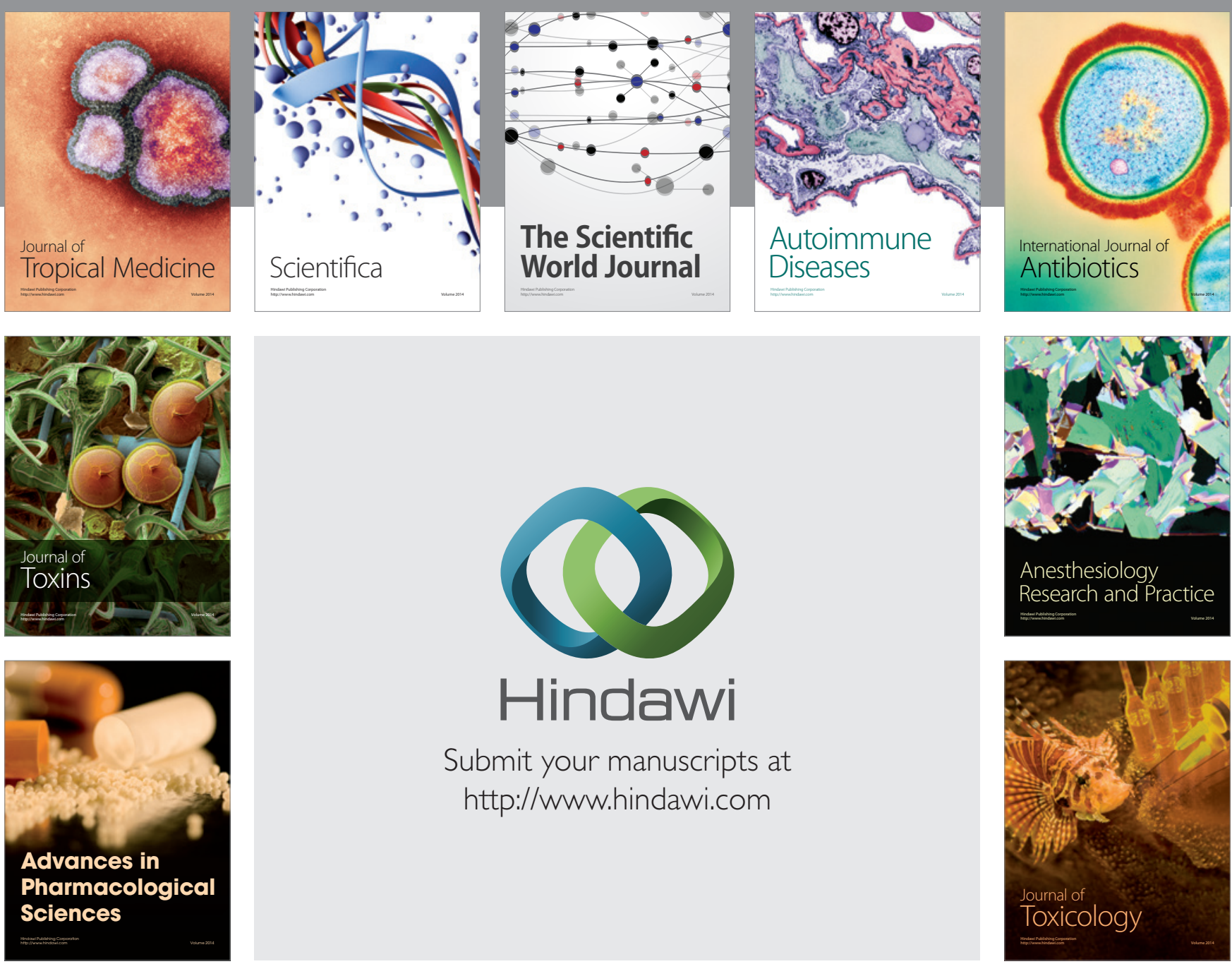

\section{Hindawi}

Submit your manuscripts at

http://www.hindawi.com
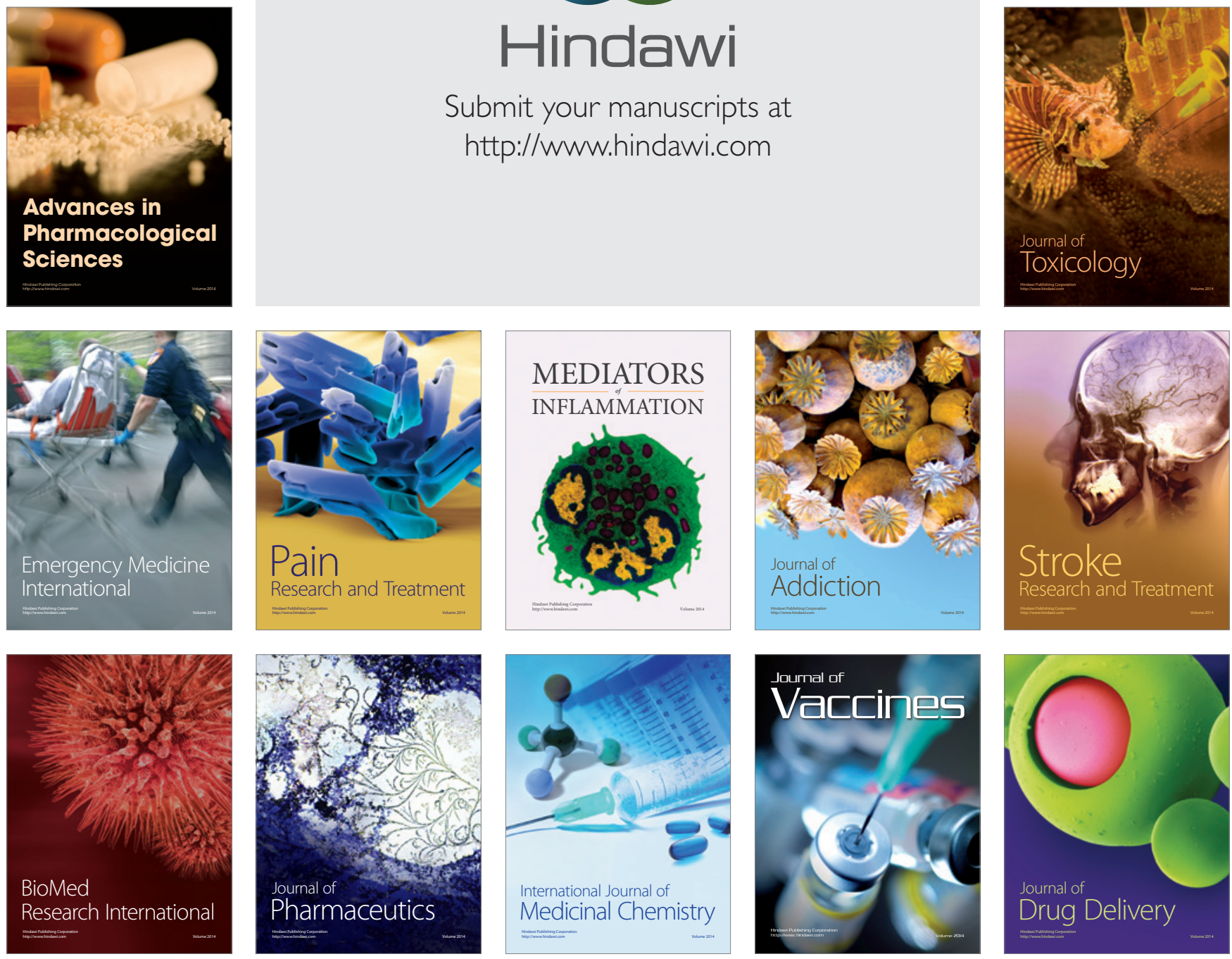